\title{
ANEURYSMS ON NEW-FORMED PRE-PAPILLARY AND PRE-RETINAL VESSELS IN PROLIFERATIVE DIABETIC RETINOPATHY*
}

\author{
BY
}

\begin{abstract}
P. H. MADSEN
From the Department of Medicine, Aarhus Amtssygehus, the Department of Ophthalmology, and the Second Clinic of Internal Medicine, Aarhus Kommunehospital, University of Aarhus, Denmark
\end{abstract}

ReTINAL micro-aneurysms were observed histologically by Mackenzie and Nettleship as early as 1879 . However, these observations passed unnoticed until 1943 when Ballantyne and Loewenstein found numerous spherical micro-aneurysms on the capillaries in flat histological sections of retinae from diabetics. These microaneurysms were conceived to be the histological substrate for the small sanguinolent spots-red dots-which are observed ophthalmoscopically in the retinae of patients with diabetes mellitus of long duration.

Since then, attempts have been made to find analogous aneurysms in other parts of the eye and in other organs, but apart from the renal glomeruli, these investigations have largely been negative (Ashton, 1958).

Biomicroscopically, aneurysms are rarely observed in the conjunctivae (Ditzel, 1962; Labram, 1964). Lundbaeck (1963) and Busacca (1964) found aneurysms on the finest vessels in patients with rubeosis iridis diabetica.

In 1888 Nettleship reported that he had ophthalmoscopically observed aneurysms on the minute vessel loops which projected forwards in front of the retina in a patient with diabetic retinitis. Ashton (1958) stated that micro-aneurysms are rarely seen on new-formed vessels in the vitreous body, although the retinal vessels themselves may show hundreds of them.

Only a few histological studies have been performed on new-formed pre-retinal vessels in proliferative diabetic retinopathy. Ballantyne and Loewenstein (1943) found pre-retinal vessels which resembled "greatly distended capillaries", but actual aneurysms were not observed. In one case, Friedenwald (1950) observed "tufts of vessels extending into the vitreous. The terminal loops of these tufts showed bulbous ends resembling the intraretinal capillary aneurysms". Cogan, Toussaint, and Kuwabara (1961) stated that proliferative vessels in the vitreous were quite different from the new-formed retinal vessels. They formed long, radial loops with few anastomoses, as distinct from the richly ramified retinal network.

\footnotetext{
* Received for publication May 3, 1965.
} 
This histological description of the vessels projecting into the vitreous is in good agreement with the ophthalmoscopic appearance of new-formed pre-retinal vessels. In the initial stages loops of a hairpin-like appearance are often observed; they are tortuous, folded, ramified, or fan-shaped-sometimes with coils of small vessels, often in their turns. The hairpin-like formation with an afferent and an efferent vessel is a typical feature (Ballantyne and Loewenstein, 1943; Jensen, 1949). Ballantyne and Loewenstein assumed that the new formation of the vessel occurred in the closed ends of capillaries.

The purpose of the study reported here was to throw light on the frequency of aneurysm-like formations on the new-formed pre-papillary and pre-retinal vessels, as observed in ophthalmoscopy and slit-lamp microscopy with the Hruby lens in patients with proliferative diabetic retinopathy, and to study the conditions under which they occur.

\section{Material}

The study comprised all the 218 diabetics who were admitted to Aarhus Amtssygehus in 1960 and most of the patients with proliferative retinopathy who were seen during the summer of 1962 in the Diabetes Clinic of Aarhus Kommunehospital, which is attended by a total of about 800 diabetic patients.

Among these patients, 25 had proliferative retinopathy in which new-formed vessels and bands of connective tissue could be distinctly observed in front of the retina. Drawings were made or, in some cases photographs were taken, of the changes observed (Figs 1 and 2).

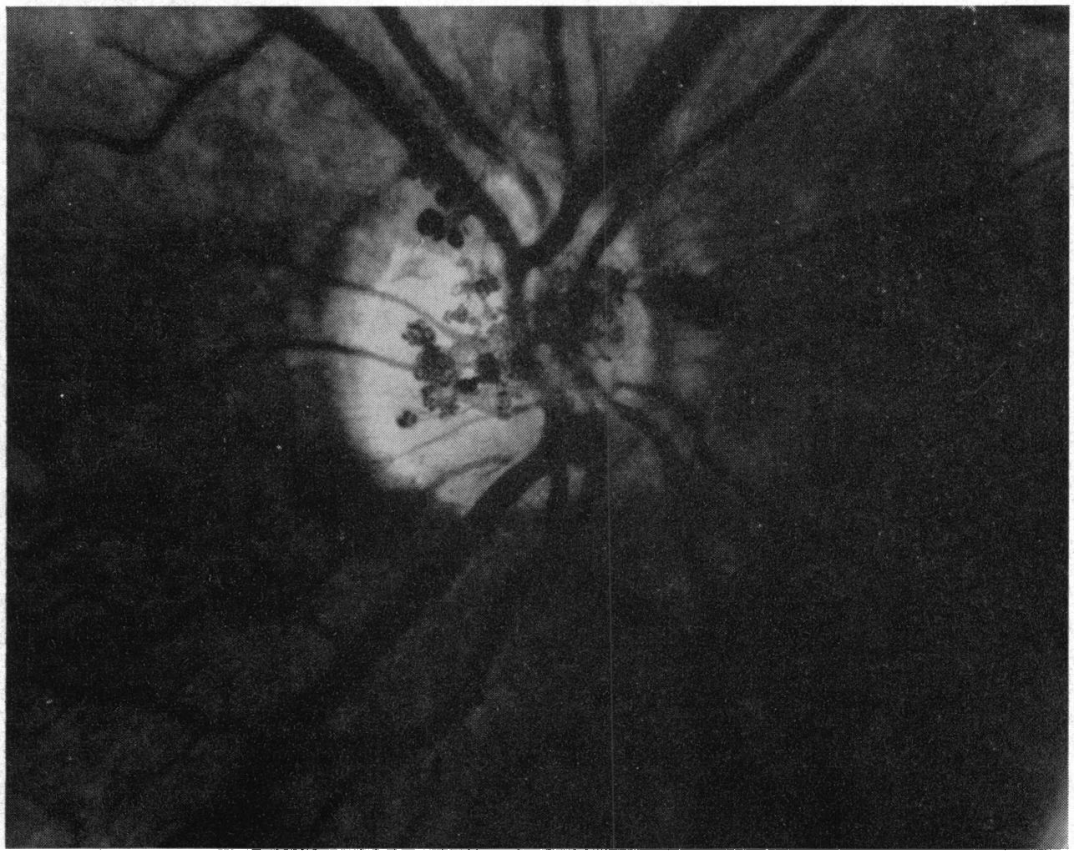

FIG. 1.-Saccular aneurysms on vessels emerging from the right superior temporal and the inferior veins in a 42-year-old man who had had diabetes for 25 years. Vascular coils in front of the middle of the optic disc. 


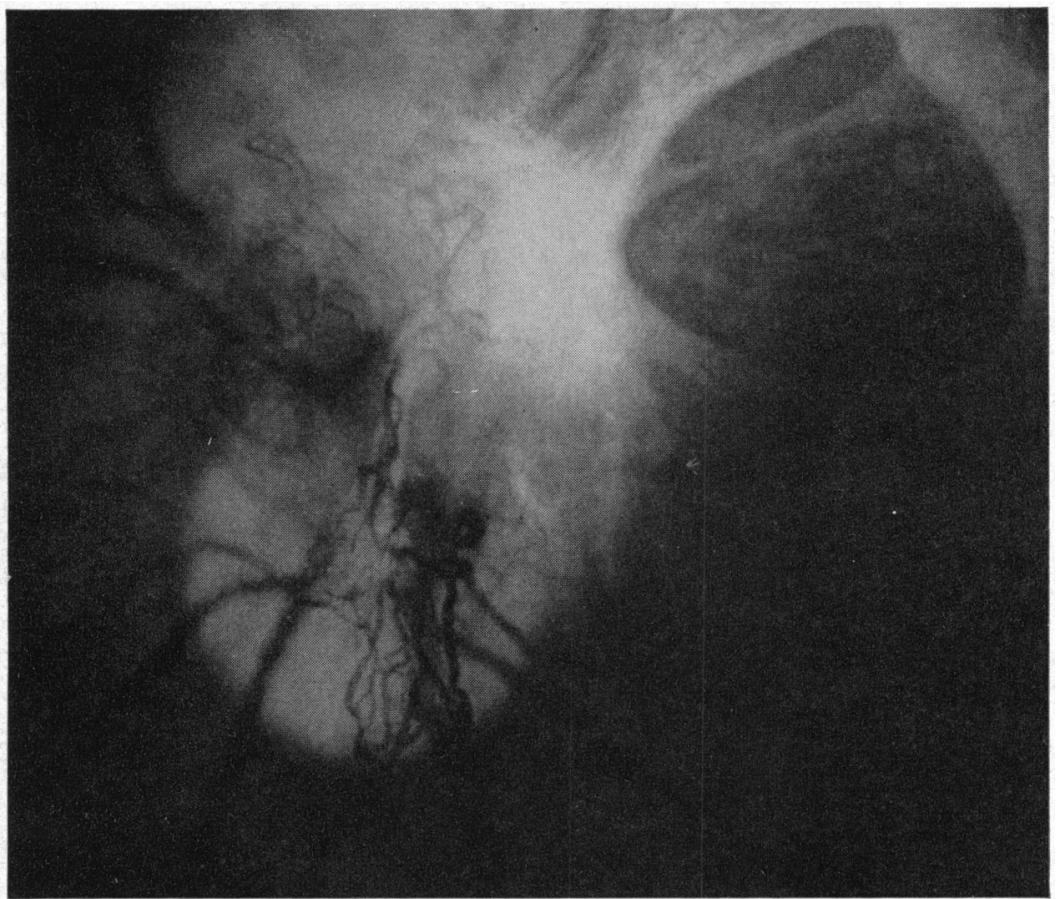

In twelve patients (13 eyes), either saccular or spindle-shaped dilatations on some of the pre-retinal vessels were revealed, while thirteen patients ( 26 eyes) did not show any ectasiae of the vessels.

The aneurysms were mainly seen in eyes with naked vascular proliferations or vascular proliferations with very slight connective tissue formation, but were absent in eyes with large masses of connective tissue (Table I).

\section{TABLE I}

Aneurysms on Pre-Retinal Vessels Related to Degree of Proliferative Retinopathy

Total no. of eyes

Naked pre-retinal vessels

Connective tissue $\left\{\begin{array}{l}\text { Veil-like } \\ \text { Moderate } \\ \text { Dense }\end{array}\right.$

Slight vascular proliferations in retina No proliferations

\begin{tabular}{cc}
\multicolumn{2}{c}{ MicRo-ANEURYSMS } \\
Present & Absent \\
13 & 37 \\
5 & 1 \\
3 & 3 \\
5 & 9 \\
0 & 13 \\
0 & 6 \\
0 & 5
\end{tabular}

Red dots, haemorrhages, exudates, and phlebopathy were present in twenty patients. Dense connective tissue proliferations concealed the retinae of both eyes in four patients. In one case only the proliferations were not accompanied by any of the other components of diabetic retinopathy. Pre-retinal haemorrhages had previously occurred in 22 of the 25 patients. 
In a follow-up study, the aneurysms were studied in ten patients for periods ranging from 1 to 4 years. The dilatations were unchanged in four cases, the aneurysm formation had increased in three, and in three other patients (4 eyes) connective tissue had partly concealed the aneurysms.

The two groups of patients with and without aneurysms on new-formed pre-retinal vessels did not differ as regards age, duration of diabetes, insulin treatment, presence or absence of proteinuria, or blood pressure. Aneurysms were present in three-fifths of the women, but only in two-fifths of the men (Table II). The visual acuity was reduced to less than 0.33 in four eyes with aneurysms, while this was the case in twenty out of 37 eyes without aneurysms.

TABLE II

Survey of Clinical Data in 25 Diabetic Patients with Pre-retinal Proliferations

\begin{tabular}{lcc} 
& \multicolumn{2}{c}{ MICRO-ANEURYSMS } \\
Present & Absent \\
Total no. of patients & 12 & 13 \\
Sex ratio, male/female & $6 / 6$ & $9 / 4$ \\
Average age in years & 41 & 48 \\
Average duration of diabetes (yrs) & 21 & 22 \\
Daily insulin dose $\{$ Less than 40 I.U. & 4 & 4 \\
More than 40 I.U. & 7 & 7 \\
Oral anti-diabetic drug & 1 & 2 \\
Proteinuria present & 5 & 7 \\
Blood pressure $\geqslant 150 / 100$ & 4 & 8 \\
Diastolic blood pressure $>110$ & 1 & 2 \\
Hypophysectomy performed & 5 & 3
\end{tabular}

\section{Discussion}

The investigation reported here showed that aneurysm-like formations-either saccular or more oblong dilatations-frequently occurred on pre-retinal vessels in patients with proliferative diabetic retinopathy.

The aneurysms were found mainly on vessels which emerged from the disc-in ten cases exclusively on such vessels (Fig. 1) and in two on both pre-papillary vessels and on vessels arising from the retina outside the disc. In one case only were aneurysms exclusively observed on new-formed vessels emerging from the retina outside the disc.

The aneurysmal or ectatic vascular areas were found on single loops of the vessels in eight cases. In two cases they were observed in the peripheral part of a fan-shaped formation and in three cases on more ramified networks or coils (Fig. 2).

It is a characteristic feature that the vascular areas which were transformed into aneurysms were naked, i.e. without accompanying connective tissue, in ten of the thirteen eyes; five of these eyes had no connective tissue at all (Table I). Furthermore, the investigation showed that the ectatic areas were found in the peripheral parts of the vessels and in the bends of the vessels, and these areas were frequently surrounded by minor haemorrhages.

Aneurysm formation on the tips of growing vessels is not, however, limited to diabetes and to the vitreous. In the cornea aneurysms have been described on new vessels by Busacca (1952), Cogan (1949), Duke-Elder and Leigh (1965), and Mann, 
Pirie, and Pullinger (1948). These aneurysms burst and haemorrhages seep between the corneal lamellae; this sequence is followed by invasion of new vessels.

In the vitreous Munro and Walker (1960) found aneurysms in patients with sicklecell disease, Wise (1956) described aneurysms on new vessels in cases of Eales's disease, and Ballantyne and Michaelson (1962) mention the frequent occurrence of minute aneurysms on capillary-like vessels in the vitreous, referring to a case with Eales's disease. Klien (1938) observed vascular coils at the tips of vascular loops in a patient suffering from hypertension.

In central venous thrombosis, pre-papillary and pre-retinal proliferations are sometimes observed. This was the case in five of the last 61 patients admitted to this department. Three of these showed saccular aneurysms similar to those described in the present series of diabetic patients.

It cannot be maintained, therefore, that aneurysms on pre-papillary and preretinal proliferations are specific for diabetes. From the present study it is not possible to elucidate any relationship between the degree of aneurysm formation on retinal and on pre-retinal vessels.

There seems to be a difference in the behaviour of the corneal and the pre-retinal vessels with aneurysms. The former may burst, giving rise to haemorrhages, after which they collapse. Around the latter, haemorrhages are often observed, but the aneurysms themselves are still present after the blood has been absorbed. In some cases pre-retinal aneurysms have been found unchanged after two to four years.

The main purpose of the present study is to point out that aneurysms on prepapillary and pre-retinal vessels are quite common, and that they may be missed if the patients are seen only after the vessels have been concealed by connective tissue. Formation of aneurysms seems to be common to all vessels invading avascular tissue and may be a consequence of some local influence exerted on the invading vessels.

\section{Summary}

Among 25 patients suffering from proliferative diabetic retinopathy, ophthalmoscopy and slit-lamp microscopy revealed aneurysm-like dilatations on new-formed pre-retinal and pre-papillary vessels in twelve cases (13 eyes). These dilatations, which were either saccular or spindle-shaped, occurred on naked vessels without accompanying connective tissue in ten of the eyes, mostly in the peripheral parts of the vessels and in the bends. The frequency of aneurysms on new-formed vessels in the vitreous body is thus considerably higher in proliferative diabetic retinopathy than has so far been assumed. Aneurysms are not, however, specific for diabetes, but seem to be common to all vessels invading avascular tissue.

\section{REFERENCES}

Ashton, N. (1958). Advanc. Ophthal., 8, 1.

Ballantyne, A. J., and Loewenstein, A. (1943). Trans. ophthal. Soc. U.K., 63, 95.

- and Michaelson, I. C. (1962). "Textbook of the Fundus of the Eye". Livingstone, Edinburgh. BusaccA, A. (1952). "Biomikroscopie und Histopathologie des Auges", vol. I. Schweizer, Zürich. (1964). "Biomicroscopie et histopathologie de l'œil, vol. II. Schweizer, Zürich. 
Cogan, D. G. (1949). Arch. Ophthal. (Chicago), 41, 406.

, Toussaint, D., and KuWABARA, T. (1961). Ibid., 66, 366.

DITZEL, J. (1962). "Konjunctivalkarrene ved diabetes mellitus". Munksgaard, Copenhagen.

Duke-Elder, S., and Leigh, A. G. (1965). "System of Ophthalmology", vol. VIII, pt 2. Kimpton, London.

Friedenwald, J. S. (1950). Amer. J. Ophthal., 33, 1187.

JENSEN, V. A. (1949). Ugeskr. Lag., 111, 1360.

Klien, B. A. (1938). Arch. Ophthal. (Chicago), $20,427$.

LABram, C. (1964). Ann. Oculist. (Paris), 197, 150.

LUNDBAECK, K. (1963). J. roy. Coll. Surg., Ireland, 1, 28.

Mackenzie, S. (1879). Ophthal. Hosp. Rep. (Lond.), 9, 134. (Microscopic examination of the eyes by Mr. Nettleship.)

Mann, I., Pirie, A., and Pullinger, B. (1948). Brit. J. Ophthal., Monogr. suppl. 13.

NeTtLeSHIP, E. (1888). Trans. ophthal. Soc. U.K., 8, 159.

Wise, G. N. (1956). Trans. Amer. ophthal. Soc., 54, 729. 